\title{
Numerical Investigation on Large Scale Eddy Structure in Unsteady Pipe Elbow Flow at High Reynolds Number Conditions with Large Eddy Simulation Approach*
}

\author{
Masaaki TANAKA** and Hiroyuki OHSHIMA** \\ **Japan Atomic Energy Agency, \\ 4002 Narita, O-arai, Ibaraki 311-1393 Japan \\ E-mail: tanaka.masaaki@jaea.go.jp
}

\begin{abstract}
Flow induced vibration in primary cooling system of the Japan Sodium cooled Fast Reactor (JSFR) has been investigated. The primary cooling system consists of a large diameter pipe and a pipe elbow with short curvature radius corresponding to its diameter (short-elbow). Flow-induced vibration by flow through the short-elbow is an important issue in design study of the JSFR, because it may affect to structural integrity of the piping. In this paper, numerical simulations for several pipe elbows with different pipe diameters and curvature radii in literature were conducted at Reynolds number conditions from $R e=500$ to $1.47 \times 10^{7}$ to investigate unsteady flow behavior through the short-elbow, including validation study of an in-house LES code (MUGTHES). Numerical results in each condition were compared with the experimental results in literature. Unsteady flow characteristics and pressure fluctuation generation mechanism in the short-elbow were clarified in relation to the large-scale eddy motion.
\end{abstract}

Key words: Fast Reactor, Pipe Elbow, Short Curvature, Large Eddy Simulation, Unsteady Horseshoe Eddy

\section{Introduction}

A conceptual design study of an advanced sodium-cooled fast reactor named as the JSFR (Japan Sodium cooled Fast Rector) has been conducted ${ }^{(1)}$. Figure 1 shows schematic view of the primary cooling system of the JSFR. Two-loop concept is adopted in the primary cooling system in order to reduce plant construction cost with compact layout. Each loop has one hot-leg piping and two ways of cold-leg piping. The hot-leg piping connects the reactor vessel and the IHX (Intermediate Heat eXchanger) integrated with the primary pump. In the hot-leg piping, the pipe diameter is $1.2 \mathrm{~m}$ and the mean velocity is 9.2 $\mathrm{m} / \mathrm{s}$ in a reference design ${ }^{(1)}$. Reynolds number in the hot-leg piping, therefore, reaches at $4 \times 10^{7}$. The hot-leg piping consists of approximately $6 \mathrm{D}$ long vertical straight pipe with bellmouth configured inlet, pipe elbow with short curvature radius $(R c)$ corresponding to its pipe diameter $(D)$ (hereinafter, such an elbow of $R c / D=1$ is called as the short-elbow) and approximately $4 D$ long horizontal straight pipe in downstream of the elbow. Since axial flow in the upstream vertical pipe turns quickly to horizontal flow through the short-elbow, it can be easily conjectured that flow through the short-elbow may be different from those through a pipe elbow with long curvature radius (hereinafter, called as the long-elbow) and that flow instability may induce in the hot-leg piping. In order to study unsteady flow characteristics through the short-elbow at high Reynolds number condition, several water

Received 7 Feb., 2012 (No. 12-0100)

DOI: 10.1299/jpes.6.210]

Copyright $\odot 2012$ by JSME 
experiments ${ }^{(2)-(5)}$ and numerical investigations ${ }^{(6)-(10)}$

have been conducted. In the experiments (2), significant pressure fluctuation with dominant frequency at approximately 0.5 in Strouhal number was observed on the pipe wall.

In this paper, numerical simulations for existing experiments of pipe elbow with different curvature radii, pipe diameters and Reynolds number conditions in $500<\operatorname{Re}<1.47 \times 10^{7}$ were performed to investigate the unsteady flow behavior in the short-elbow pipe and to clarify the pressure fluctuation generation mechanism which could cause significant mechanical vibration on the JSFR hot-leg piping. Before the simulations, existing studies for the pipe elbow flow in literature were surveyed. Representative experimental conditions from the surveyed studies were employed as boundary conditions in the simulations. An in-house numerical simulation code of MUGTHES ${ }^{(23,24)}$ was used in this study. Numerical results at a laminar flow condition and at turbulent flow conditions were compared with experimental results in axial velocity and pressure profiles. The power spectral density (PSD) of the pressure fluctuation in downstream of the elbow as a numerical result was compared with that of the experimental result. Through the numerical simulations, flow characteristics in the shortelbow pipe were specified and the relation between characteristic unsteady threedimensional flow structures and significant pressure fluctuation generation was discussed.

\section{Nomenclature}

Cs Coefficient in Smagorinsky model (-)

$D \quad$ Pipe diameter $(\mathrm{m})$

$D_{i j} \quad$ Shear strain tensor $\left(\mathrm{s}^{-1}\right)$

$W_{i j} \quad$ Rotation component $\left(\mathrm{s}^{-1}\right)$

$P \quad$ Pressure $(\mathrm{Pa})$

$P_{0} \quad$ Dynamic pressure $\left(=\rho V^{2} / 2\right)(\mathrm{Pa})$

$\triangle P \quad$ Pressure drop of the elbow $(\mathrm{Pa})$

$P_{u} \quad$ Pressures at $l_{u}$ upstream from the elbow inlet $(\mathrm{Pa})$

$P_{d} \quad$ Pressures at $l_{d}$ downstream from the elbow outlet $(\mathrm{Pa})$

$Q \quad$ Second invariant of velocity gradient tensor $\left(\mathrm{s}^{-2}\right)$

$Q_{0} \quad$ Representative value of $Q\left(=\left(V_{0} / D\right)^{2}\right)\left(\mathrm{s}^{-2}\right)$

$R \quad$ Pipe radius $(=D / 2)(\mathrm{m})$

$R c \quad$ Curvature radius of pipe elbow (m)

Re Reynolds number (-)

$V \quad$ Time averaged axial velocity component $(\mathrm{m} / \mathrm{s})$

$V_{a} \quad$ Axial velocity component in Eq. (1) $(\mathrm{m} / \mathrm{s})$

$V_{0} \quad$ Mean velocity at inlet $(\mathrm{m} / \mathrm{s})$

$V$, Fluctuation intensity of axial velocity component $(\mathrm{m} / \mathrm{s})$

$l_{u} \quad$ Distance from the elbow inlet $(\mathrm{m})$

$l_{c} \quad$ Distance from the elbow inlet to its outlet along center axis $(\mathrm{m})$

$l_{d} \quad$ Distance from the elbow outlet (m)

$n \quad$ Constant of a power law

$r \quad$ Radial position in pipe (m)

$u, v, w$ Velocity components in physical space $(\mathrm{m} / \mathrm{s})$

$x, y, z$ Axis in physical space (m)

$\Delta t \quad$ Time interval (s)

$\beta \quad$ Modification coefficient $(=\zeta / \zeta)$

( $\beta_{1}$ is for $1 / 3$-scaled and $\beta_{2}$ is for $1 / 10$-scaled water experiments)

$\lambda \quad$ Friction factor of pipe 
$\lambda_{e} \quad$ Friction factor of the elbow part (-)

$\theta \quad$ Angle from inlet to outlet of elbow at curvature center $\left(^{\circ}\right)$

$\rho \quad$ Density of fluid $\left(\mathrm{kg} / \mathrm{m}^{3}\right)$

$\zeta \quad$ Total pressure loss coefficient of the elbow (-)

$\zeta$ Total pressure loss coefficient of the elbow in the short domain (-)

$\zeta_{0} \quad$ Contribution of dynamic pressure in the upstream buffer tank $(=1.0)(-)$

$\zeta_{\text {add }}$ Additional pressure loss coefficient consisting of $\zeta_{0}, \zeta_{\text {in }}$ and friction loss of straight pipe in the short domain (-)

$\zeta_{e} \quad$ Pressure loss coefficient of the elbow without friction loss (-)

$\zeta_{\text {in }} \quad$ Pressure loss coefficient of bell-mouth configured inlet $(=0.02)(-)$

$\zeta_{t} \quad$ Total pressure loss coefficient of test section (-)

\section{Existing Studies for Pipe Elbow Flow}

A pipe elbow is usually used as one of the most important components in transportation piping system of an industrial plant. A number of studies for the flow in curved pipes and bends were well summarized, for example, by S.A. Berger et al. ${ }^{(11)}$. Most of early investigations were on the flow through a curved pipe with relatively large curvature radius focusing on the secondary flow pattern characterized by counter rotating flows on transversal cross section ${ }^{(12,13)}$ and also the pressure loss in the pipe elbows ${ }^{(14,15)}$.

A few investigations on pipe elbow flow in a short curvature radius $(R c / D \leq 3)$ were found in literature ${ }^{(17)-(22)}$ and they were listed in Table 1 including recent experiments for the JSFR hot-leg piping investigation ${ }^{(2)-(5)}$. As a notable study, Frried and Idelchik (16) proposed a useful classification on the trend of the total resistance (pressure loss) coefficient for the curved duct with a short curvature radius into three regimes as function of Reynolds number. When the Reynolds number $(R e)$ was over $2 \times 10^{5}$, this region was called as the post-critical regime and the pressure loss coefficient kept almost constant. The region in $R e<10^{5}$ was called as the sub-critical regime and the pressure loss coefficient showed a large value. The region between $R e=10^{5}$ and $R e=2 \times 10^{5}$ was called as the transition regime in which the pressure loss coefficient decreased sharply as increasing of Reynolds number. In the sub-critical regime, axial velocity profiles in the long-elbow piping were measured by P. H. M. Bovendeerd et al. ${ }^{(17)}$, Enayat et al. ${ }^{(18)}$ and Sudo et al ${ }^{(19)}$. Kawamura, et al. ${ }^{(20)}$ and Yuki, et al. (21) measured axial velocity profiles of water flow in several elbows with relatively small curvature at turbulent flow conditions from the transition regime to the beginning of post-critical regime. Coffield et al. ${ }^{(22)}$ measured the total pressure loss coefficients in the smooth surface finished pipe elbow of $R c / D=1.2$ in the post-critical regime of $2 \times 10^{5}<R e<4 \times 10^{7}$. Useful information related to the short-elbow flow at very high Reynolds number conditions $\left(\operatorname{Re}>5 \times 10^{5}\right)$ in the post-critical regime could be obtained by

Table 1 Existing experiments for pipe elbow flow

\begin{tabular}{|c|c|c|c|c|}
\hline Conductors & $\operatorname{Re}$ & $R c / D$ & $D(\mathrm{~m})$ & Working Fluid \\
\hline Bovendeerd et al. ${ }^{(17)}$ & 700 & 3 & 0.008 & Mixed Oil \\
\hline Enayat et al. ${ }^{(18)}$ & $500,1093,4.3 \times 10^{4}$ & 2.8 & 0.048 & Water \\
\hline Sudo et al. $^{(19)}$ & $6 \times 10^{4}$ & 2 & 0.104 & Air \\
\hline Kawamura, et al. ${ }^{(20)}$ & $5 \times 10^{4}, 5 \times 10^{5}$ & $0.55,1,2$ & 0.1 & Water \\
\hline Yuki, et al. ${ }^{(21)}$ & $1.4 \times 10^{4}, 4.84 \times 10^{4}$ & $1,1.5,2$ & 0.056 & Water \\
\hline Coffield et al. $^{(22)}$ & $2 \times 10^{5} \sim 4 \times 10^{7}$ & 1.2 & 0.132 & Water \\
\hline Shiraishi, et al. ${ }^{(2)}$ & $3.2 \times 10^{5} \sim 8.6 \times 10^{6}$ & 1 & 0.413 & Water \\
\hline Iwamoto et al. ${ }^{(3),(32)}$ & $5 \times 10^{4}, 3.2 \times 10^{5}$ & 1 & 0.125 & Water \\
\hline Ono, et al. ${ }^{(4)}$ & $5.4 \times 10^{5}$ & $1,1.5$ & 0.15 & Water \\
\hline $\begin{array}{l}\text { Ebara, et al. }{ }^{(5)} \\
\text { and Yuki, et al. }\end{array}$ & $3.2 \times 10^{5} \sim 1 \times 10^{6}$ & 1 & 0.127 & Water \\
\hline
\end{tabular}


the several experiments ${ }^{(2)-(5),(32),(33)}$ and the Coffield's measurement ${ }^{(22)}$. Shiraishi et al. ${ }^{(2)}$ measured pressure loss coefficient of the test section and axial velocity profiles of water flow in the post critical regime of $3.2 \times 10^{5}<R e<8.0 \times 10^{6}$ by using the Laser Doppler Velocimetry (LDV) technique. The test section was fabricated as $1 / 3$-scaled model of the JSFR hot-leg piping as shown in Fig. 1 (b) and diameter of the test section was of $0.41 \mathrm{~m}$. The maximum mean velocity in the experiment was $9.2 \mathrm{~m} / \mathrm{s}$ which corresponded to that in the operation condition of the JSFR. Iwamoto et al., ${ }^{(3,32)}$ also measured the pressure loss coefficient in $2 \times 10^{4}<\operatorname{Re}<3.2 \times 10^{5}$ and the axial velocity profiles of water flow with the LDV. The short-elbow pipe test section with diameter of $0.125 \mathrm{~m}$ was fabricated as $1 / 10$-scaled model of the JSFR hot-leg piping. Ono, et al., ${ }^{(4)}$ measured velocity field by the Particle Image Velocimetry (PIV) technique at $R e<5.4 \times 10^{5}$ in the elbows of $R c / D=1$ and 1.5. The test section was as 1/8-scaled model of the JSFR hot-leg piping and pipe diameter was 0.15 m. Yuki et al., ${ }^{(33)}$ and Ebara et al., ${ }^{(5)}$ have also been conducted water experiment using a test section with a short-elbow pipe.

\section{Numerical Simulations of Unsteady Pipe Elbow Flow}

\subsection{Numerical Conditions}

A numerical simulation code named as MUGTHES ${ }^{(23,24)}$ to analyze unsteady thermalhydraulic phenomena in the fast breeder reactors was used in this study. MUGTHES employs the large eddy simulation (LES) approach in boundary fitted coordinate system to simulate unsteady thermal-hydraulic phenomena in the reactor. The governing equations are discretized with the finite volume approach ${ }^{(25)}$ and finite differential scheme in collocated grid system. In the LES approach of the MUGTHES, the sub-grid scale turbulent viscosity is evaluated with standard Smagorinsky model ${ }^{(26)}$ and artificial wall conditions derived by a wall function law is utilized ${ }^{(24)}$. The Crank-Nicolson method is used for time integration and the Projection method ${ }^{(27)}$ is used to solve velocity field. The second order central differential scheme is used for all terms in governing equations. In this study, the Smagorinsky model constants of $C s=0.1$ for low Reynolds number conditions $\left(\operatorname{Re}<1 \times 10^{5}\right)$ and $C s=0.14$ for high Reynolds number conditions $\left(R e>1 \times 10^{5}\right)$ were empirically selected.

\subsection{Mesh Arrangements}

Applicable mesh arrangement for the pipe elbow flow was already investigated in the

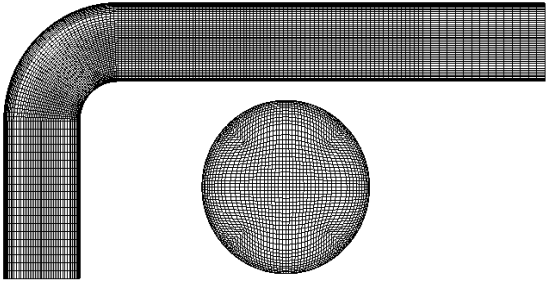

(a) $R c / D=1$ of small diameter pipe elbow

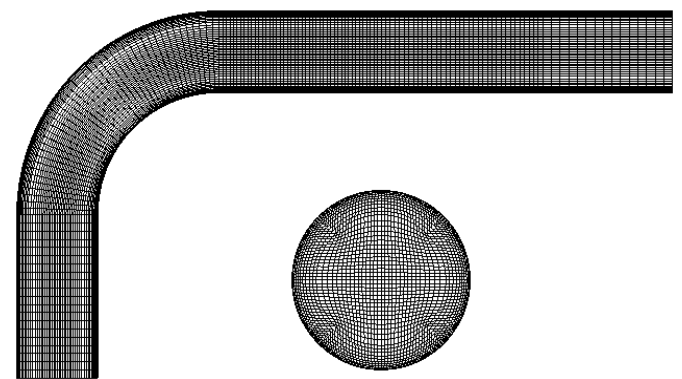

(b) $R c / D=2$ of small diameter pipe elbow

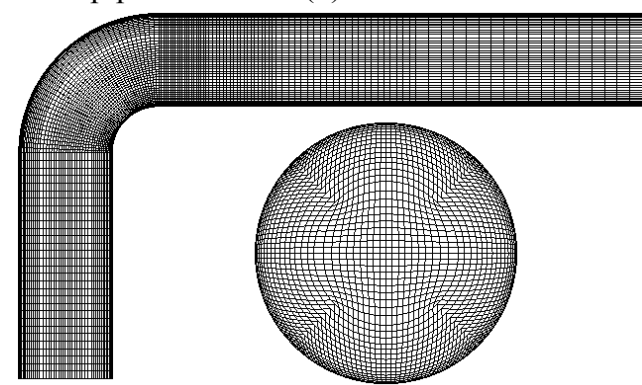

(c) $R c / D=1$ of large diameter pipe elbow

Fig. 2 Mesh arrangements for various pipe elbow configurations. 
previously study ${ }^{(10)}$. Figures 2 (a) and (b) respectively show mesh arrangements for different curvature ratios of $R c / D=1$ and 2 at laminar and relatively low $R e$ number turbulent flow conditions $\left(\operatorname{Re}<5 \times 10^{5}\right)$ based on the $1 / 10$-scaled water experiment $(D=0.125$ m). The mesh arrangement in Fig. 2(a) had $3.875 \times 10^{5}$ cells with 20 layers in the upstream pipe, 95 layers in $5.6 D$ long downstream pipe from the elbow outlet and 40 layers in the elbow. The mesh arrangement in Fig. 2(b) had $4.0 \times 10^{5}$ cells with 20 layers in the upstream pipe, 100 layers for $5.6 \mathrm{D}$ long downstream pipe from the elbow outlet and 45 layers in the elbow. In the both meshes, $2,500(=50 \times 50)$ cells were commonly distributed on each crosssection and the minimum cell size on the wall was $0.004 D$ in radial direction. The other mesh arrangement for the long-elbow pipe of $R c / D=3$ was also employed in Sec. 3.3, though it was not shown in Fig. 2. For the $R c / D=3$ piping, the mesh arrangement in up- and downstream pipes was the same with that of the $R c / D=2$ elbow as shown in Fig. 2(b) and the layer thickness in the elbow was 1.5 times longer than that of the $R c / D=2$ elbow as the curvature radius length. Figure 2(c) shows a mesh arrangement for the $1 / 3$-scaled water experiment. Total cell number was $3.75 \times 10^{5}$ with 30 layers in $2.4 D$ long upstream pipe, 80 layers in approximately $5.2 \mathrm{D}$ long downstream pipe from the elbow outlet and 40 layers in the short-elbow. $2,500(=50 \times 50)$ cells were distributed on a cross-section and the minimum cell size on the wall was $1.35 \mathrm{~mm}(=0.0033 D)$ in radial direction.

\subsection{Fundamental Flow Characteristics in Different Curvature Radius at Laminar Flow Conditions}

Before the investigation of short-elbow flow at very high Reynolds number condition in the post-critical regime ${ }^{(16)}$, simulations at a laminar flow condition at $R e=500$ in different curvature radii from $R c / D=1$ to 3 were performed in order to validate numerical schemes of MUGTHES with boundary fitted coordinate system and to know fundamental characteristics of the short-elbow flow in comparisons with those in the long-elbows because it wasn't much revealed as mentioned in Chap. 2. Experimental results at $R e=700$ (17) was compared with numerical results after reaching developed flow state at typical positions in the elbow. Meshes in Figs. 2(a) and (b) were respectively used for the elbows of $R c / D=1,2$. Water at $20^{\circ} \mathrm{C}$ was working fluid in the simulations. Parabolic axial velocity profile was set at the inlet to simulate the experimental conditions. Non-slip condition was applied on the pipe wall.

Figures from Fig. 3(a) to Fig. 3(e) show axial velocity components along radius direction at typical positions of (a) elbow inlet as $0^{\circ}$, (b) $39.8^{\circ}$, (c) $81.9^{\circ}$, (d) $0.5 D$ and (e) $5 D$. In each figure, vertical axis in each figure shows the normalized radial positions from the inner wall $(r / D=-0.5)$ to the outer wall $(r / D=0.5)$ through the center of the pipe and each lateral axis shows axial velocity component $\left(V_{a}\right)$ normalized by the mean velocity at inlet $\left(V_{0}\right) . V_{a}$ in the elbow is reproduced with the velocity components $(v, w)$ in Cartesian coordinate system on the symmetric axial plane and the angle $(\theta)$ from the inlet $\left(0^{\circ}\right)$ to the outlet $\left(90^{\circ}\right)$ of the elbow at the curvature center, as follows.

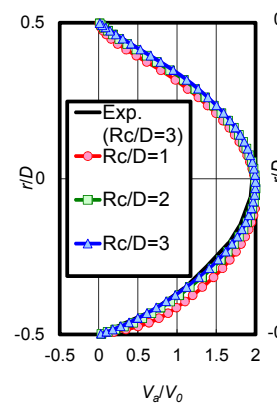

(a) elbow inlet $\left(0^{\circ}\right)$

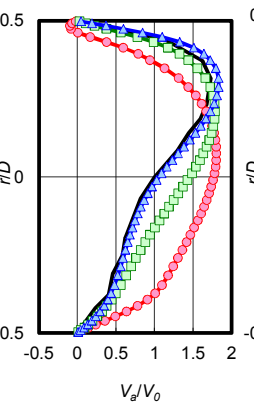

(b) $39.8^{\circ}$

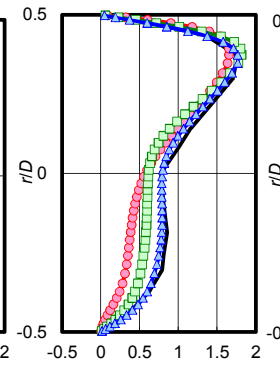

$v_{a} / V_{o}$

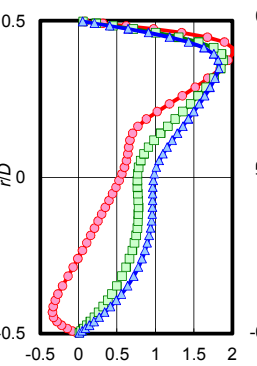

$v_{a} / V_{0}$

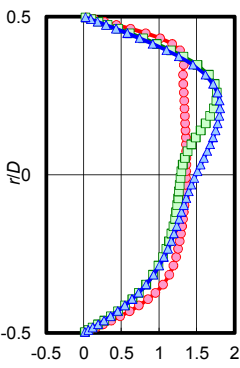

$V_{\mathrm{a}} / V_{0}$

Fig. 3 Radial profiles of axial velocity at $\mathrm{Re}=500$ in several curvature radius conditions. (Experimental results of $R c / D=3$ were at $R e=700$.) 


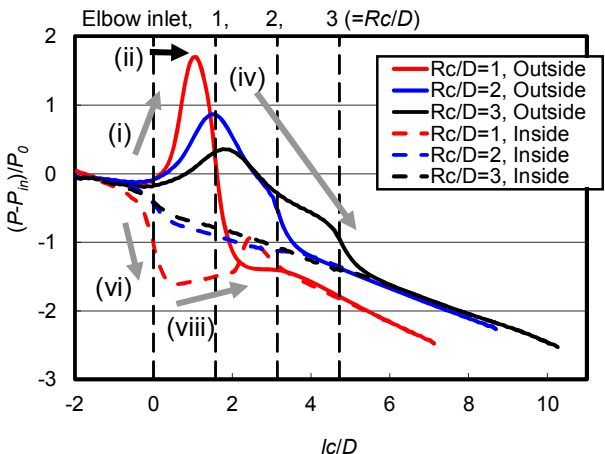

(a) Pressure drop

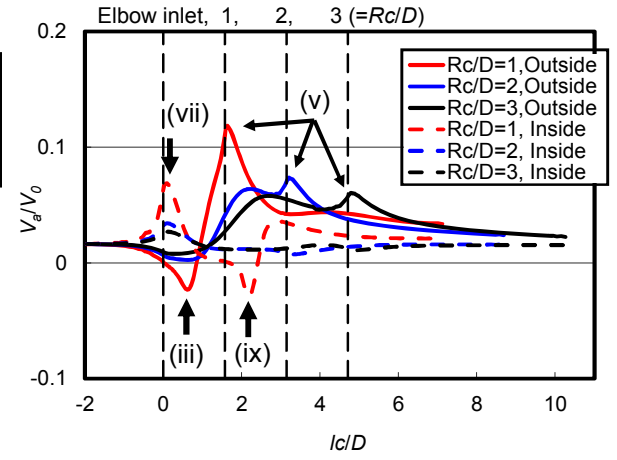

(b) Axial velocity

Fig. 4 Axial profiles of pressure drop and axial velocity component near outer and inner walls and along center axis of elbow pipe.

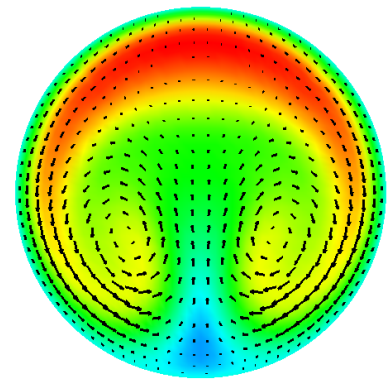

(a) $\mathrm{S} 0(R c / D=1)$

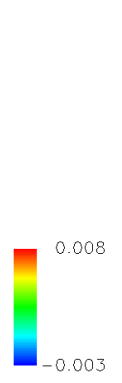

$(\mathrm{m} / \mathrm{s})$

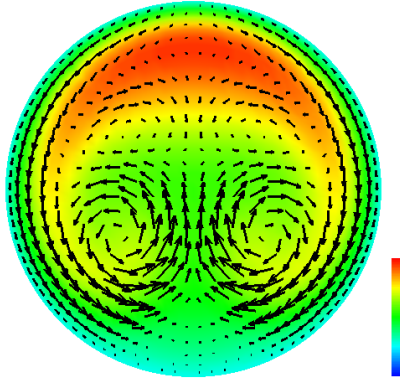

(b) $\mathrm{L} 0(R c / D=2)$

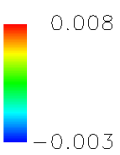

$(\mathrm{m} / \mathrm{s})$

Fig. 5 Axial velocity component and velocity vector on the transversal cross section in $0.5 D$ downstream of the elbow outlet at $R e=500$.

$$
V_{a}=\left[(v \cos \theta)^{2}+(w \sin \theta)^{2}+2 v w \sin \theta \cos \theta\right]^{1 / 2}
$$

$V_{a}$ corresponds to $v$ in $\theta<0^{\circ}$ and $w$ in $\theta>90^{\circ}$, respectively.

In Figs. 3 (a), (b) and (c), numerical results of $R c / D=3$ showed good agreement with the experimental results. At the elbow inlet as shown in Fig. 3(a), the maximum velocity position was slightly moved from pipe center axis to inner wall side in all elbows because of the high pressure distribution on the outside in the elbow as shown in Fig. 4(a). In upstream part of the elbow as shown in Fig. 3(b), the axial velocity profile was much affected by the curvature radius and the maximum axial velocity position was relocated at outer wall side region due to the inertia of the axial flow. In downstream part of the elbow as shown in Fig. 3(c), the maximum axial velocity were located at the almost same position on outer wall side in each elbow though the axial velocity profiles in inner region were slightly affected by the curvature ratio. Axial flow in $R c / D=1$ much decelerated from the middle part as in Fig. 3(b) to the downstream part as in Fig. 3(c). At $0.5 D$ downstream of the elbow as shown in Fig. 3(d), flow separation occurred near the inner wall $(r / D \sim-0.5)$ and adverse flow appeared in the short-elbow $(R c / D=1)$ though flow separation was not shown in the long-elbows $(R c / D=2$ and 3). In far downstream from the elbow as shown in Fig. $3(\mathrm{e})$, the axial velocity profiles recovered to that of developed flow in the straight pipe.

Figures 4 (a) and (b) relatively show axial profiles of (a) pressure drop and (b) axial velocity component in Eq. (1) along the lines traced on the outer and the inner walls. Figures 5(a) and (b) respectively show axial velocity component and velocity vectors at odd number grids on the transversal cross section in $0.5 D$ downstream from the elbow outlet at $R e=500$. Elbow flow as shown in Figs. 4(a) and (b) was to be explained with the Roman numerals from (i) to (ix) appearing in the figures. On the outer wall side of the elbow, pressure increased along the flow direction (i) and magnitude of the pressure in the short- 
elbow was higher than those in the long-elbows (ii) because the mainstream impinged on the outer wall in the short-elbow while it easily flowed along the outer wall in the longelbows. In the short-elbow, flow separation with reverse flow region occurred in upstream part of the elbow where the adverse pressure gradient along the flow direction showed the maximum value (iii). Pressure in the elbow gradually decreased along the flow direction after the maximum pressure was shown (iv). At the elbow outlet, steep favorable pressure gradient was shown and so the axial flow accelerated locally (v). On the inner wall side of the elbow, the pressure profile in the short-elbow was quite different from those in the longelbows. In the long-elbows, the favorable axial velocity preserved and flow separation did not occur because favorable pressure gradient was kept along the flow direction. On the contrary, axial flow was rapidly increased by the favorable steep pressure gradient in the short-elbow (vi). After the maximum velocity appeared (vii), axial flow was decreased by the adverse pressure gradient (viii) from middle part to downstream part of the short-elbow. The flow separation, therefore, occurred due to the axial flow deceleration ${ }^{(28)}$ in the downstream of the elbow (ix). As for the secondary flow well-known as Dean vortex ${ }^{(12)}$, it was necessarily induced due to the pressure difference between outer and inner regions in the short-elbow as shown in Fig. 5(a) and also in the long-elbow Fig. 5(b). And it induced radial flow from the inner wall to the pipe center.

\subsection{Transition from Sub-Critical Regime to Post-Critical Regime}

Numerical simulations at turbulent flow conditions in relatively low Reynolds numbers listed in Table 2 were conducted to investigate the dependency of the pipe elbow flow on the curvature ratio and the inlet velocity profile in the sub-critical and the early post-critical regimes. The mesh in Fig. 2(a) was used for the short-elbow cases of S1, S2 and S2a and the mesh in Fig. 2(b) was for the long-elbow cases of L1 and L2. As for the inlet boundary conditions, axial velocity profile by using a power law of $n=1 / 6.5$ was for S1 and L1 and $n=1 / 9$ was for S2 and L2 to simulate developed flow condition in the experimental condition. And fixed flat axial velocity profile was assumed in S2a to investigate influence of the inlet velocity profile. Transient calculations with time interval of $\Delta t=0.1 \mathrm{~ms}$ in the sub-critical regime cases of S1 and $\mathrm{L} 1$, and of $\Delta t=0.05 \mathrm{~ms}$ in the post-critical regime cases of S2 and S2a were respectively conducted for $1.5 \times 10^{5}$ steps from an initial state. After reaching quasi-developed flow state, statistical analyses were done by using last 5,000 data at sampling interval of $10 \Delta t$ in each case.

Figures 6(a) and (b) respectively show radial profiles of the time averaged axial velocity and the axial velocity fluctuation intensity in (1) $0.55 D$ and (2) $1 D$ downstream from the elbow outlet. Lateral axes in Figs. 6(a-1) and (a-2) shows the time averaged axial velocity component of $V$ in Eq. (1) normalized by the inlet mean velocity of $V_{0}$ and those in Figs. 6(b-1) and (b-2) shows normalized fluctuation intensity of the axial velocity component of $V^{\prime} / V_{0}$. Vertical axis in each figure shows radial position from the center axis $(r)$ normalized by the pipe diameter $(D)$ from the inner wall $(r / D=-0.5)$ to the outer wall $(r / D=0.5)$ of the pipe. In time average field as in Figs. 6(a-1) and (a-2), the numerical results showed almost agreement with the experimental results, except at $0.5 D$ downstream in short-elbow as in Fig.6(a-1). In the field of fluctuation intensity as in Figs. 6(b-1) and (b-2), the numerical results could follow the experimental results in each case. While the stream

Table 2 Boundary conditions for turbulence flow condition

\begin{tabular}{|c|c|c|c|c|c|}
\hline & $V_{0}(\mathrm{~m} / \mathrm{s})$ & $\operatorname{Re} \times 10^{5}$ & $R c / D$ & Inlet velocity & Comparable data \\
\hline $\mathrm{S} 1$ & 0.403 & 0.5 & \multirow{3}{*}{1.0} & \multirow{2}{*}{$\begin{array}{c}\text { Power } \\
\text { law }\end{array}$} & Ref.(20,21) \\
\hline $\mathrm{S} 2$ & 4.03 & 5.0 & & & Ref.(20) \\
\hline $\mathrm{S} 2 \mathrm{a}$ & 4.03 & 5.0 & & Uniform & Ref.(4) \\
\hline L1 & 0.484 & 0.6 & \multirow{2}{*}{2.0} & \multirow{2}{*}{$\begin{array}{c}\text { Power } \\
\text { law }\end{array}$} & Ref.(19,20) \\
\hline $\mathrm{L} 2$ & 4.03 & 5.0 & & & Ref.(20) \\
\hline
\end{tabular}


went in narrow region near the outer wall at the laminar condition as in Fig. 3(d) and Figs. 5(a) and (b), main stream widely existed in upper half of the pipe $(r / D>0)$ at turbulence flow conditions. Local acceleration in inner wall position $(r / D<-0.25)$ could be predicted by the numerical simulation. Axial velocity fluctuation was high in this inner wall region $(r / D<-0.25)$ and the maximum fluctuation intensity shown in the center region of the pipe $(r / D \sim 0)$ was caused by the interaction between the axial main stream and the radial flow from the inner wall caused by the secondary flow.

Figures 7(a) and (b) respectively show instantaneous distributions of (a) the axial velocity component in Eq. (1) by color painting on the symmetrical axial cross section and (b) the axial velocity component and velocity vectors at odd number grids on the transversal cross section in $0.5 D$ downstream from the elbow outlet in (1) $\mathrm{S} 1$ at $R e=5 \times 10^{4}$ and (2) L1 at $R e=6 \times 10^{4}$. Mainstream existed in the center region of the elbow in the turbulence flow

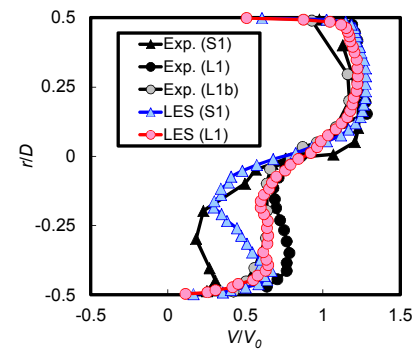

(a-1) $0.55 D$

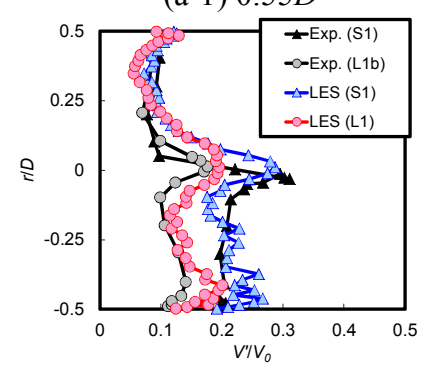

(b-1) $0.55 D$

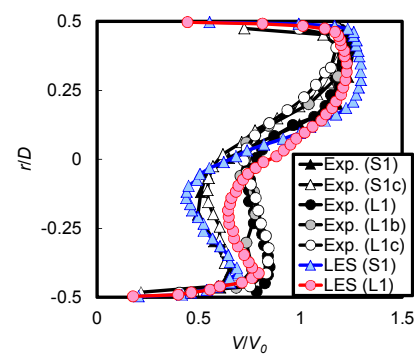

(a-2) $1.0 D$

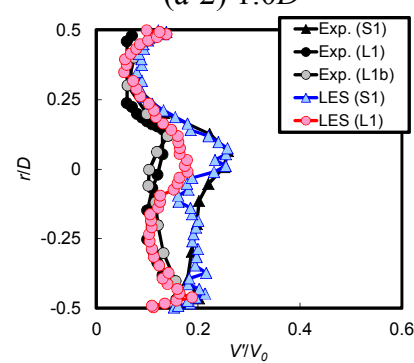

(b-2) $1.0 D$

Fig. 6 Radial profiles of (a) time averaged axial velocity and (b) axial velocity fluctuation intensity. Experimental result of $\mathrm{Llb}$ was of $R c / D=2$ at $R e=5 \times 10^{4}(20)$ and the results of S1c and L1c were respectively of $R c / D=1$ and 2 at $R e=4.84 \times 10^{4(21)}$.
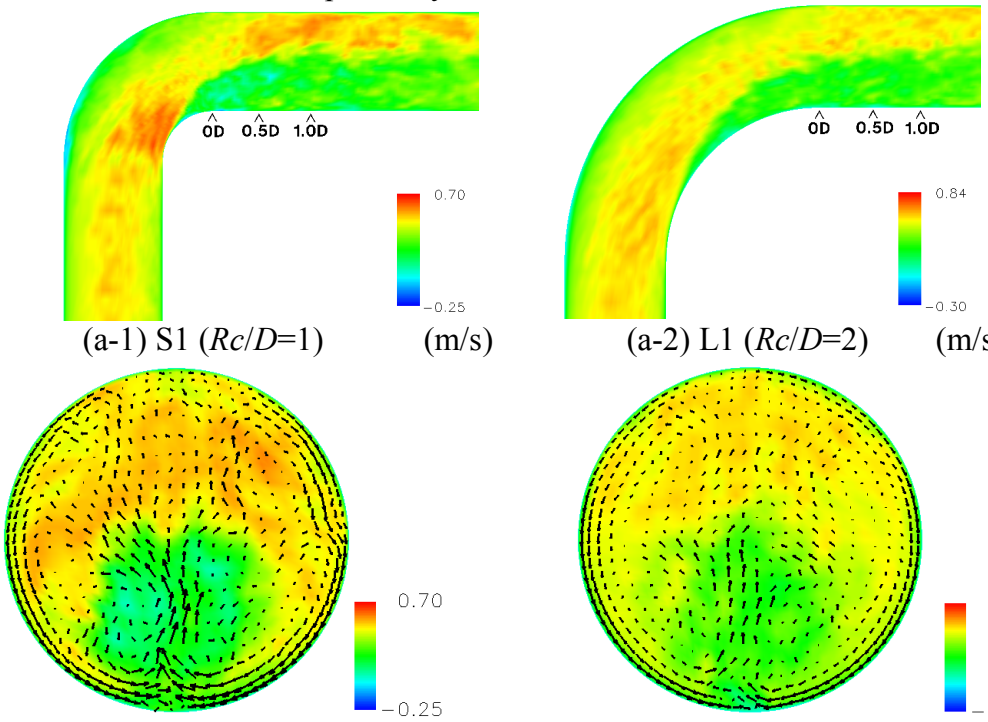

(b-1) $\mathrm{S} 1(R c / D=1)$

$(\mathrm{m} / \mathrm{s})$

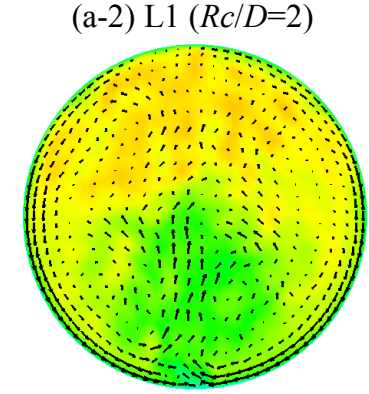

(b-2) L1 $(R c / D=2)$ $(\mathrm{m} / \mathrm{s})$

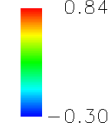

$(\mathrm{m} / \mathrm{s})$

Fig. 7 Instantaneous distributions of (a) axial velocity component on the symmetric axial cross section and (b) axial velocity component and velocity vector on the transversal cross section in $0.5 D$ downstream of the elbow outlet. 
conditions though it flowed in the narrow area on the outer wall side in laminar flow condition as shown in Figs. 5(a) and (b). In both elbows in Figs. 7(a-1) and (a-2), axial flow went through the inner wall side region at near the elbow inlet due to the high pressure on the outer wall side (see Fig.10). In the short-elbow as in Fig. 7(a-1), axial flow accelerated in the inner wall side region in upstream part of the elbow and flow separation occurred in downstream part of the elbow. In the long-elbow as in Fig. 7(a-2), the axial flow slightly accelerated in upstream part of the elbow and the axial flow was preserved along mainstream direction. In both elbows in Fig. 7(b-1) and (b-2), secondary flow consisting of oncoming circumferential streams along the wall surface appeared on the transversal crosssection and radial flow from the inner wall to the pipe center was formed. The secondary flow pattern was not symmetrical and it was deformed at instantaneous pictures as shown in Figs. 7(b-1) and (b-2) though symmetric oncoming rotating vortexes could be obtained on the transversal cross section in time average filed. The oncoming streams on both sides collided in the inner wall side region and collision point periodically swayed from side to side from moment to moment. Yuki et al. (21) and Iwamoto et al. (3) suggested such an unsteady swing motion of the secondary flow in downstream of the elbow by the water experiment. In the inner region $(r / D<-0.25)$, the local acceleration of axial flow and the axial velocity fluctuation intensity as shown in Figs. 6(b-1) and (b-2) were caused by this collision of circumferential flows.

Figures 8(a) and (b) shows radial profiles of (a) time averaged axial velocity and (b) fluctuation intensity of S2, S2a and L2 at $R e=5 \times 10^{5}$ in (1) $0 D$, (2) $0.55 D$ and (3) $1 D$ downstream from the elbow outlet. Lateral axes in Figs. 8(a-1), (a-2) and (a-3) show the normalized time averaged axial velocity component $V / V_{0}$ and those in Figs. 8(b-1), (b-2) and (b-3) show the normalized fluctuation intensity of the axial velocity component $V^{\prime} / V_{0}$. Vertical axis in each figure shows normalized radial position from inner wall $(r / D=-0.5)$ to outer wall $(r / D=0.5)$ of the elbow. In the time average field as shown in Figs. 8(a-1), (a-2) and (a-3), numerical results in each case were not far from the experimental results. The numerical results in $0 D$ at the elbow outlet as in Fig. 8(a-1) and $1 D$ downstream from the elbow as in Fig. 8(a-3) almost agreed with the experimental results. In $0.55 D$ downstream from the elbow as in Fig. 8(a-2), the numerical results followed trend of the experimental results. As for the fluctuation intensity as shown in Figs. 8(b-1), (b-2) and (b-3), the peak position of the maximum fluctuation intensity could simulate the experimental results in

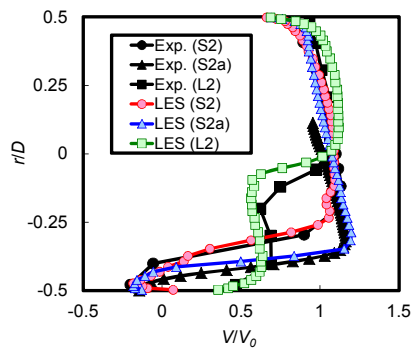

(a-1) $0 D$

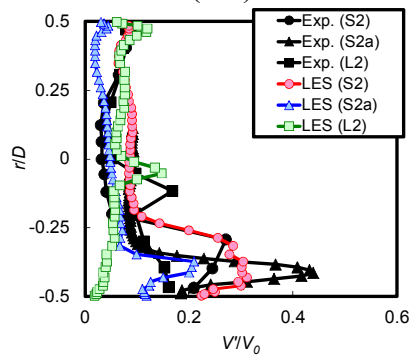

(b-1) $0 D$

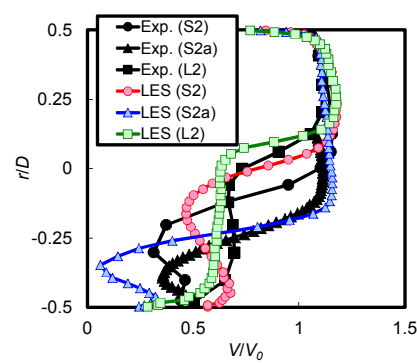

(a-2) $0.55 D$

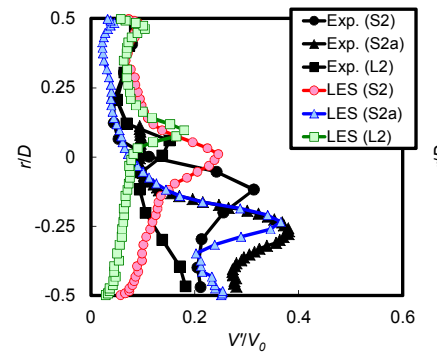

(b-2) $0.55 D$

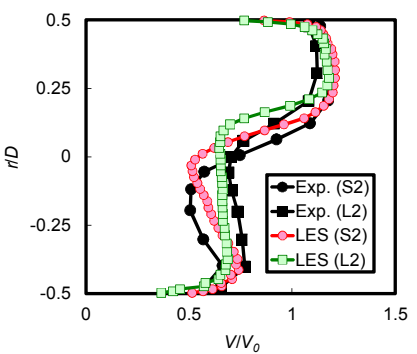

(a-3) $1 D$

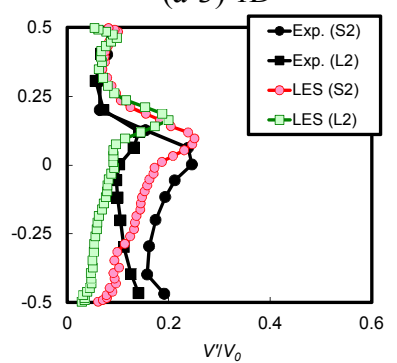

(b-3) $1 D$

Fig. 8 Radial profiles of (a) time averaged axial velocity and (b) axial velocity fluctuation intensity at $R e=5 \times 10^{5}$ in different inlet velocity profile conditions and at curvature ratios. 
each case though the numerical results were inclined to underestimate the fluctuation intensity in the inner wall side region. Small fluctuation intensity in the inner region was caused by the symmetric secondary flow pattern reproduced in S2 and L2 in $0.5 D$ downstream of the elbow (see Figs. 9(b-1) and (b-3)). On the contrary, the unsteady circumferential flow could successfully be reproduced in S2a as shown in Fig. 9(b-2) and so the numerical result agreed with the experimental result as shown in Fig. 8(b-2). In S2a with recirculation flow due to flow separation in the elbow, unstable flow caused in the elbow reached at reattachment point and flow instability in the flow went back to the separation point by the recirculation flow. So the unsteady flow motion may be continuously produced owing to the flow instability as a trigger. Such instability can be served as turbulence fluctuation at inlet boundary. But, the providing method of adequate fluctuation which can consider scales of eddy and spatial distribution in a target system (experiment) is under development in the MUGTHES.

Figures 9 (a) and (b) show instantaneous distributions of (a) axial velocity component on the symmetric axial cross section and (b) axial velocity component and velocity vectors at odd number grids on the transversal cross section in $0.5 \mathrm{D}$ downstream of the elbow outlet in (1) S2, (2) S2a and (3) L2. Due to the high pressure region widely distributed on the outer wall side region, axial flow was pushed away from the outer region and main stream could exist on the inner side in center part of the elbow (see Fig. 7(a) and Fig. 9(a)) In S2a with undeveloped inlet flow profile, flow separation occurred in downstream of the elbow as shown in Fig. 9(a-2). On the transversal cross section, symmetric secondary flow could be formed in each elbow case in S2 as in Fig. 9(b-1) and L2 as in Fig. 9(b-3) and unsteady swing motion observed in S1 and L1 as shown in Fig. 7(b-1) and (b-2) could not be reproduced by the simulation. Therefore, small fluctuation intensity was induced in S2 and L2 as shown in Figs. 8(a-2) and (b-2) comparing with the experimental results. The radial flow from inner wall to center part was induced by collision of on-coming circumferential streams as shown in Fig. 9(b-1) and Fig. 9(b-3). The radial flow enhanced by the symmetric secondary flow could push up the mainstream from the inner wall side region so that the numerical results in time averaged field were at upper positions from the experimental results. Thus, reproduction of the unsteady secondary flow was essentially important for accurate prediction of the pipe elbow flow in the simulation.

Figures 10(a) and (b) respectively show axial profiles of the pressure drop and the axial velocity component in Eq. (1) at boundary cells on outer (solid line) and inner (dotted line)
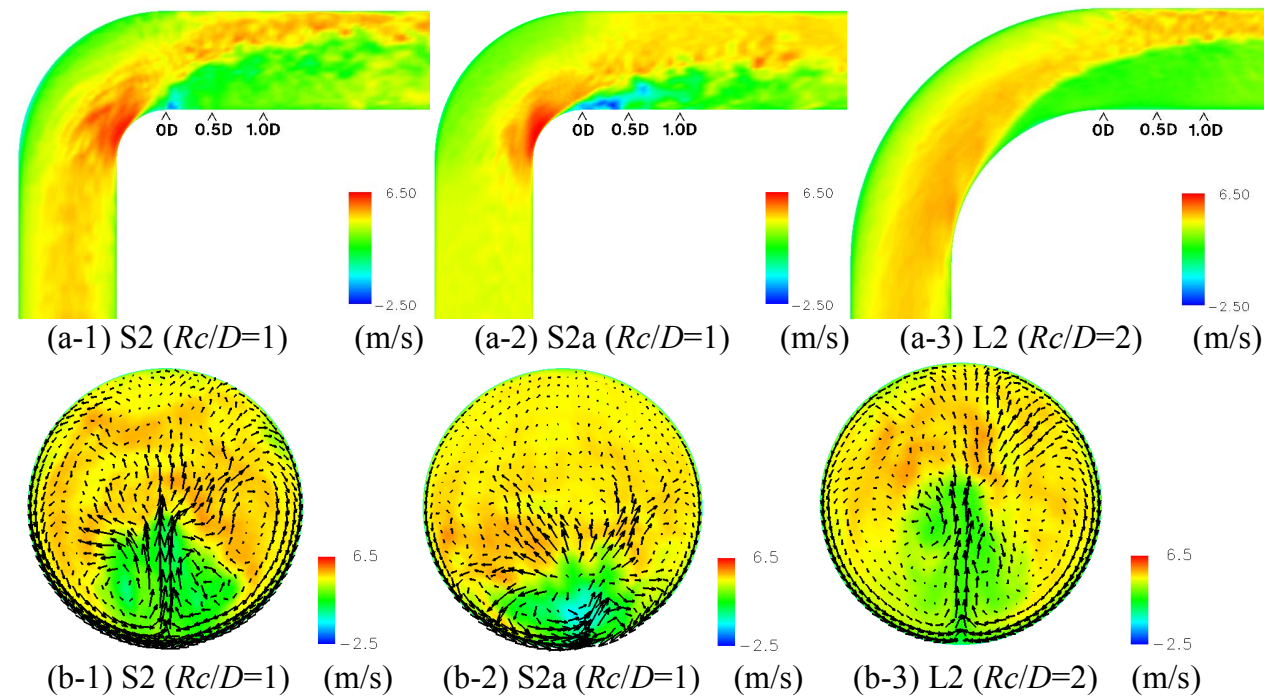

Fig. 9 Instantaneous distributions of (a) axial velocity component on the symmetric axial cross section and (b) axial velocity component and velocity vectors on the transversal cross section in $0.5 D$ downstream of the elbow outlet in (1) S2, (2) S2a and (3) L2. 


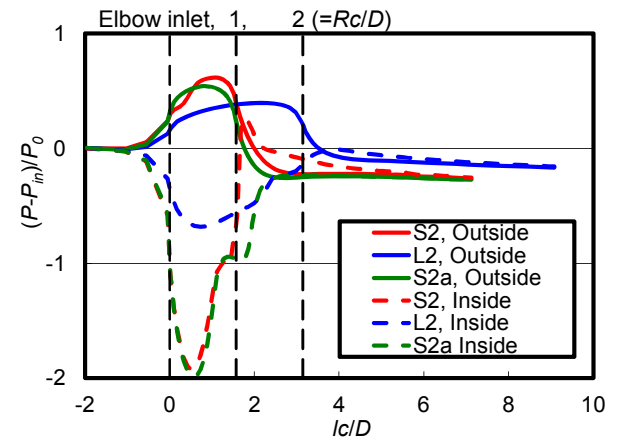

(a) Pressure drop

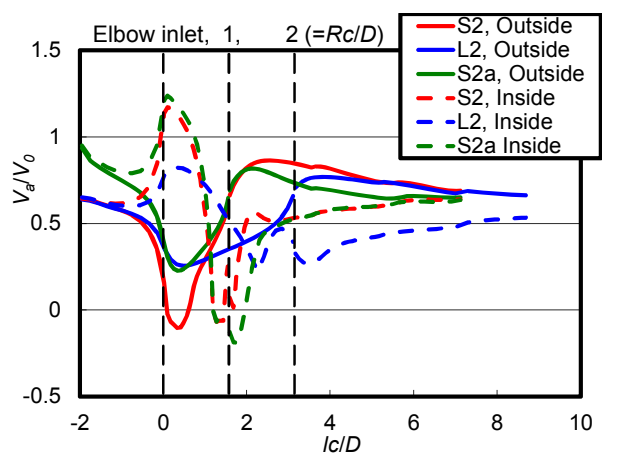

(b) Axial velocity

Fig. 10 Axial profiles of (a) pressure drop and (b) axial velocity component near outer and inner walls along center axis of elbow pipe at $R e=5 \times 10^{5}$.

walls along center axis of elbow pipe at $R e=5 \times 10^{5}$. In the outside region, adverse pressure gradient decreased the axial velocity. When boundary layer was developed in the upstream straight pipe as in the S2 short-elbow case with developed flow inlet condition, flow separation could locally occur in the outside region in upstream part of the elbow as shown in Fig. 10 (b). In downstream of the elbow, the axial flow locally accelerated due to the steep favorable pressure gradient in the outside region. In the inner region, the favorable pressure gradient increased the axial flow velocity. The maximum velocity in the shortelbows of S2 and S2a was approximately 1.5 times higher than that in the long-elbow of L2 because magnitude of the pressure gradient in the short-elbow was much steeper than that in the long-elbow. Axial velocity gradually decreased in the short- and long-elbows due to the adverse pressure gradient in downstream part of the elbow. In S2 at developed inlet flow condition, axial flow once separated and soon attached on the inner wall and pressure recovered rapidly at the elbow outlet. On the contrary, axial flow in S2a at undeveloped inlet flow condition separated from the inner wall and adverse flow existed in the downstream of the elbow and low pressure was shown to $l c / D \sim 2$ as reattachment point. As mentioned in Sec.3.3, the secondary flow on the transversal cross section was caused in the elbow due to the pressure difference on the transversal cross section. In S2 with developed inlet flow condition, the circumferential flow could easily be generated due to the small inertia area near the wall as the developed boundary layer near the pipe wall and the secondary flow was successfully formed on the transversal cross section. Although the axial flow separated in the elbow as shown in Fig. 10(b), it soon attached on the inner wall owing to the developed secondary flow which could convey the fluid from the outer wall side region to the inner wall side region. In S2a with undeveloped inlet flow condition, axial flow occupied wide area on the cross section and thin boundary layer prevented the secondary flow development in the elbow. The weak secondary flow, therefore, couldn't convey the fluid from outer region to the inner wall side region. At the moment, the stream could separate from the wall and the separation bubble ${ }^{(30)}$ with adverse flow could be formed. In the long-elbow of L2, the secondary flow could generate as the same mechanism in S2 so that flow separation didn't occur in the elbow. In short, the obvious flow separation could occur in the short-elbow $(R c / D=1)$ and not in the long-elbow $(R c / D=2)$. In the shortelbow, the separation bubble could continuously be formed at undeveloped inlet flow condition but it was intermittently formed at developed inlet flow condition.

\subsection{High Reynolds Number Turbulent Flow Conditions in Post Critical Regime}

\subsubsection{Numerical conditions}

Numerical simulations at high Reynolds number conditions in post-critical regime listed in Table 3 were conducted. Boundary conditions were employed from the 1/3-scaled 
Table 3 Boundary conditions for 1/3-scaled experiment

\begin{tabular}{ccccc}
\hline & $V_{0}(\mathrm{~m} / \mathrm{s})$ & $\operatorname{Re} \times 10^{6}$ & $\Delta t(\mathrm{~ms})$ & \multirow{2}{*}{ Working Fluid } \\
\cline { 1 - 4 } FA & 0.8 & 0.32 & 0.5 & \\
\cline { 1 - 4 } FB & 3.0 & 1.2 & 0.1 & \multirow{2}{*}{ Water at $20{ }^{\circ} \mathrm{C}$} \\
\cline { 1 - 4 } FC & 7.0 & 2.9 & 0.05 & \\
\hline FS & \multirow{2}{*}{9.2} & 3.7 & 0.05 & \\
\cline { 1 - 4 } FH & & 8.0 & 0.05 & Water at $60{ }^{\circ} \mathrm{C}$ \\
\hline FN & 9.2 & 14.7 & 0.05 & Sodium at $550^{\circ} \mathrm{C}$ \\
\hline
\end{tabular}

water experiment simulating the hot-leg piping of the JSFR ${ }^{(2)}$. Diameter of the piping as test section was $0.41 \mathrm{~m}$ and the short-elbow $(R c / D=1)$ was installed. In the experiment, fluid pressure on the wall and axial velocity profiles at several Reynolds number conditions between $3.2 \times 10^{5}$ and $8.0 \times 10^{6}$ in the post-critical regime were measured. The mesh in Fig. 2 (c) was used in the numerical simulations. The numerical results of FA, FB, FC, FS and FH could be compared with the experimental results. FN was hypothetical case with liquidsodium at $550{ }^{\circ} \mathrm{C}$ as working fluid simulating the JSFR condition in the $1 / 3$-scaled experiment. Fixed flat profile of the axial velocity was set at the inlet boundary surface, according to the measured profile at $2 D$ upstream from the elbow inlet. After reaching quasi-developed flow state, transient calculation was done for $1.5 \times 10^{5}$ steps from an initial state at a time interval $\Delta t$ as in Table 3 and statistical analyses were done by using last 5,000 data at sampling interval of $10 \Delta t$.

\subsubsection{Pressure loss coefficient of elbow}

The pressure loss coefficients of the numerical results, experimental results and empirical equations in literature were compared to confirm adequacy of the numerical results. Total pressure loss coefficient of the elbow $(\zeta)$ is defined as follows ${ }^{(15)}$.

$$
\begin{aligned}
& \zeta=\Delta P / P_{0}=\Delta P /\left(\rho V_{0}^{2} / 2\right) \\
& \Delta P=\left(P_{u}-P_{d}\right)-\lambda\left(l_{u}+l_{d}\right)\left(\rho V_{0}^{2} / 2\right) / D
\end{aligned}
$$

$P_{0}$ is dynamic pressure and $\Delta P$ is the pressure drop of the elbow. $P_{u}$ and $P_{d}$ are pressures at $l_{u}$ upstream from the elbow inlet and at $l_{d}$ downstream from the elbow outlet, respectively. $\lambda$ is friction factor of pipe.

Ito ${ }^{(15)}$ proposed the empirical equation for total pressure loss coefficient of the elbow $\left(\theta=90^{\circ}\right)$ as follows.

$$
\begin{aligned}
& \zeta=0.00241 \alpha \theta \operatorname{Re}^{-0.17}(R c / R)^{0.84} \\
& \alpha=0.95+17.2(R c / R)^{-1.96}
\end{aligned}
$$

Here, $R$ is radius of pipe. This correlation can be used for $2 \times 10^{4}<R e<4 \times 10^{5}$. Another correlation for the $90^{\circ}(=\theta)$ elbow was proposed by Frried and Idelchik ${ }^{(16)}$ using a friction factor formulation of the pipe ${ }^{(16)}$ as follows.

$$
\begin{aligned}
& \zeta=0.21(R c / D)^{-1 / 2}+0.0175 \theta \lambda(R c / D) \\
& \lambda=(1.8 \times \log (R e)-1.64)^{-2} \quad(\text { for } R e>4000)
\end{aligned}
$$

And $\zeta$ could also be estimated with the Pigott's equation ${ }^{(31)}$ for the pressure loss coefficient of the elbow without friction loss and the friction factor of the elbow part $\left(\lambda_{e}\right)$ by using $\lambda$ in Eq. (7) as follows.

$$
\zeta_{e}=0.157(R c / D)^{-2}+97.6 \lambda^{1.5}(R c / D)^{-0.5}
$$




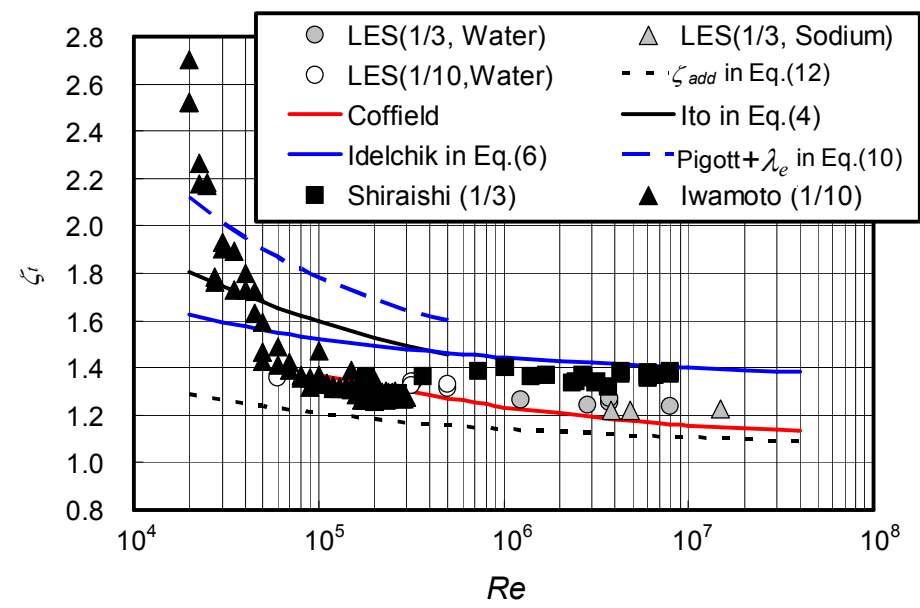

Fig. 11 Total pressure loss coefficient of test section in the $1 / 3$-scaled experiment with coefficients estimated by $1 / 10$-scaled experiment and empirical equations.

$$
\begin{aligned}
& \lambda_{e}=\lambda\left(l_{c} / D\right)=2 \pi \lambda R c /(4 D)=\pi \lambda R c /(2 D) \\
& \zeta=\zeta_{e}+\lambda_{e}=0.157(R c / D)^{-2}+97.6 \lambda^{1.5}(R c / D)^{-0.5}+0.5 \lambda \pi(R c / D)
\end{aligned}
$$

Shiraishi et al. ${ }^{(2)}$ measured the total pressure loss coefficient of test section $\left(\zeta_{t}\right)$ in the $1 / 3$-scaled experiment. $\zeta_{t}$ was estimated by the static pressure in upstream buffer tank and the pressure on the straight pipe at $4.25 D$ downstream from the elbow outlet through the $5.76 D$ long straight pipe with bell-mouth configured inlet in upstream of the elbow. Since $P_{d}$ in Eq. (3) for the total pressure loss estimation must be measured at more than $50 D$ downstream from the elbow outlet to eliminate influence of the unsteady flow through the elbow ${ }^{(15)}, \zeta_{t}$ obtained by the $1 / 3$-scaled experiment was different from $\zeta$ in Eq. (2) and also the pressure loss coefficient estimated by the numerical results in a short domain. Therefore, modification coefficient of $\beta(=\zeta / \zeta)^{(15)}$ was introduced in order to compare the coefficients among experiments, empirical equations in literature and numerical results. The $\zeta$ is total pressure loss coefficient of the elbow in short $l_{d}$ in Eq. (3). Then, the coefficient $\zeta$ was modified to the pressure loss coefficient of the test section with $\beta_{1}=0.75$ as follows.

$$
\begin{aligned}
& \zeta_{t}=\zeta^{\prime}+\zeta_{\text {add }}=\beta_{1} \zeta+\zeta_{\text {add }} \\
& \zeta_{\text {add }}=\zeta_{0}+\zeta_{\text {in }}+\lambda\left(l_{u}+l_{d}\right) / D \\
& \zeta_{t}=0.75 \zeta+\zeta_{\text {add }}=0.75 \zeta+[1.0+0.02+(5.76+4.25) \lambda]
\end{aligned}
$$

In Eq.(12), $\zeta_{0}(=1.0)$ was contribution of dynamic pressure in the upstream buffer tank and $\zeta_{\text {in }}(=0.02$ as tentative) was of the bell-mouth configured inlet. $\lambda$ is friction factor of pipe in Eq. (7).

Iwamoto et al. ${ }^{(32)}$ also estimated the pressure loss coefficient of the elbow pipe $\zeta_{t}$ based on pressure difference between $3 D$ upstream from the elbow inlet and $5 D$ downstream from the elbow outlet in the $1 / 10$-scaled experiment. The total pressure loss coefficient of the elbow $\zeta$ could be estimated by $\zeta_{t}$ with modification coefficient $\beta_{2}=0.76$ ${ }^{(15)}$ from the short domain and the friction loss of $8 D$ long pipe as follows.

$$
\zeta=\left\{\zeta_{t}{ }_{t}-(5+3) \lambda\right\} / \beta_{2}
$$

And then, $\zeta_{t}$ in the 1/10-scaled experiment could be compared with $\zeta_{t}$ in the $1 / 3$-scaled experiment after the modification with Eq. (11) and (14) as follows.

$$
\zeta_{t}=\beta \zeta+\zeta_{\text {add }}=0.75\left[\left(\zeta_{t}^{\prime}-(5+3) \lambda\right) / \beta_{2}\right]+\zeta_{\text {add }}
$$


Figure 11 shows total pressure loss coefficient of the test section in the $1 / 3$-scaled experiment $^{(2)}$ in $3.2 \times 10^{5}<\operatorname{Re}<8.0 \times 10^{6}$ and estimated coefficients from the $1 / 10$-scaled experiment in $2 \times 10^{4}<R e<3 \times 10^{5}$ and those of the empirical equations. By the Coffield's experiment ${ }^{(22)}$, it was shown that the pressure loss coefficient of the elbow was not changed drastically in $\operatorname{Re}>10^{7}$, though the coefficient curve slightly decreased in the post-critical regime. The pressure loss coefficients of the 1/3-scaled experiment and those of the numerical results in Table 2 and 3 were located in between the estimation curves between the Idelchik's equation in Eq. (6) and the Coffield's experiment. Although the numerical results slightly underestimated the coefficients of the 1/3-scaled experiment, the adequacy of the numerical results in this paper was confirmed.

\subsubsection{Axial Velocity Profiles at High Reynolds Number conditions}

Figures 12(a) and (b) show radial profiles of (a) the time averaged axial velocity and (b) the fluctuation intensity of FA at $R e=3.2 \times 10^{5}, \mathrm{FB}$ at $R e=1.2 \times 10^{6}, \mathrm{FC}$ at $R e=2.9 \times 10^{6}$ and FS at $R e=3.7 \times 10^{6}$ in (1) $0.18 \mathrm{D}$, (2) $0.62 \mathrm{D}$ and (3) $1.12 \mathrm{D}$ downstream from elbow outlet compared with the experimental results. Lateral axes in Figs. 12(a-1), (a-2) and (a-3) show the normalized time averaged axial velocity component $V / V_{0}$ and those in Figs. 12(b-1), (b2) and (b-3) show the normalized fluctuation intensity of the axial velocity component $V^{\prime} / V_{0}$. Vertical axis in each figure shows radial position normalized by pipe diameter from inner wall $(r / D=-0.5)$ to outer wall $(r / D=0.5)$ of the elbow. As for the comparable data at $R e=3.2 \times 10^{5}$ at $0.18 D$ as in Fig. $12(\mathrm{a}-1)$, time averaged data was only obtained in the $1 / 3$ scaled experiment and data in the $1 / 10$-scaled experiment at $R e=3.2 \times 10^{5(3)}$ was presented in Fig. 12(a-1) and (b-1). The time averaged axial velocity and fluctuation intensity of FA at $R e=3.2 \times 10^{5}$ in $0.18 D$ downstream from the elbow outlet as shown in Fig.12 (a-1) and (b-1) corresponded to both experimental results of $1 / 3$ - and $1 / 10$-scaled experiments at $R e=3.2 \times 10^{5}$. In the $1 / 3$-scaled experiment, radial profiles of the measured results at each Reynolds number condition in $3.2 \times 10^{5}<\operatorname{Re}<3.7 \times 10^{6}$ also corresponded to each other. The numerical results as shown in Fig. 12 almost agreed with the experimental results and the similar axial velocity profiles were shown. Dependency on the Reynolds number was not distinctive in the time averaged axial velocity profile though a little difference appeared in

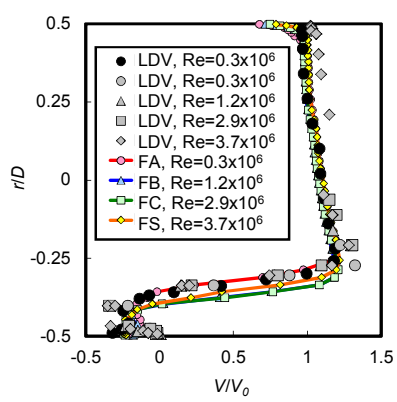

(a-1) $0.18 D$

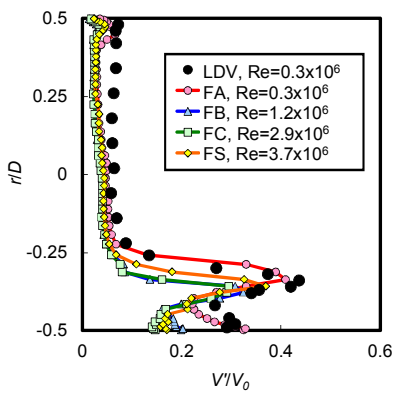

(b-1) $0.18 D$

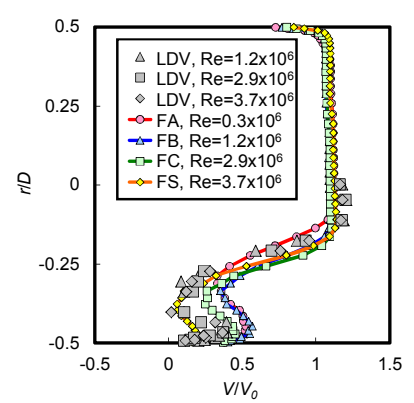

(a-2) $0.62 D$

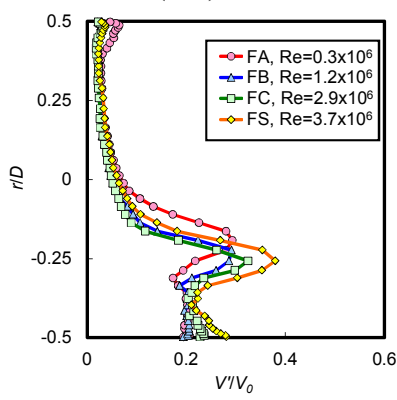

(b-2) $0.62 D$

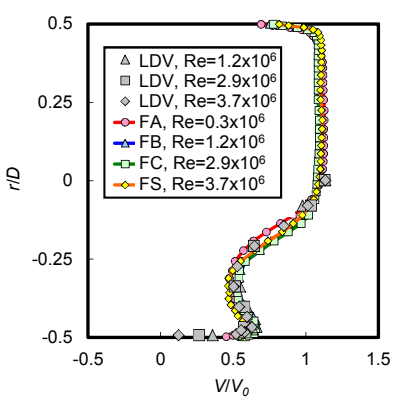

(a-3) $1.12 D$

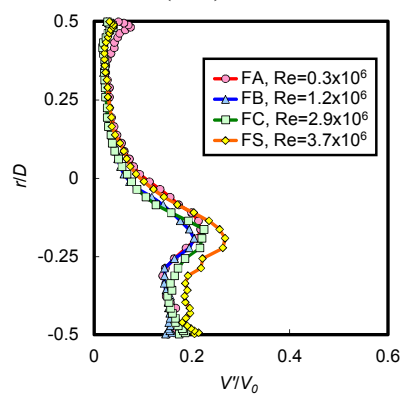

(b-3) $1.12 D$

Fig. 12 Radial profiles of (a) time averaged axial velocity and (b) axial velocity fluctuation intensity. (• : experimental results at $R e=3.2 \times 10^{5}$ were from Ref. (3)) 


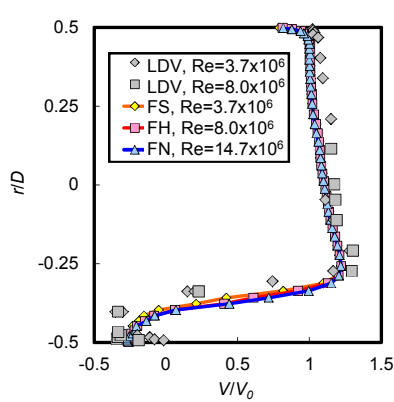

(a) $0.18 D$

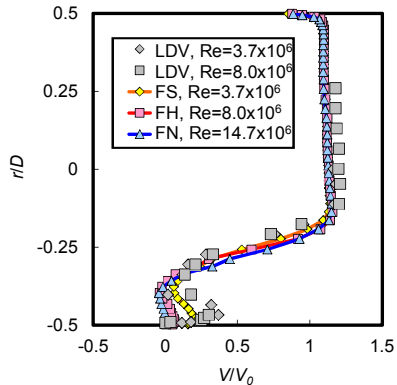

(b) $0.62 D$

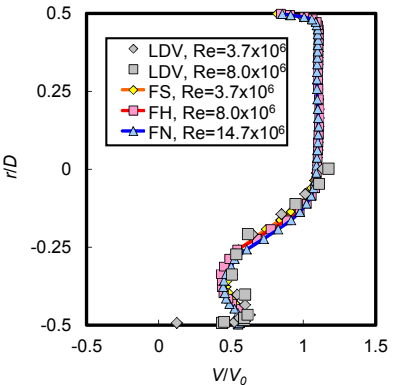

(c) $1.12 D$

Fig. 13 Radial profiles of time averaged axial velocity.

the inner wall side region $(r / D<-0.25)$ as in Fig. 12(a-2) in the numerical results. Recirculation region was shown in $0.18 D$ downstream of the elbow as in Fig. 12(a-1), and the mainstream attached on the inner wall in front of $0.62 D$ downstream of the elbow as in Fig. 12(a-2). This was consistent with the experimental result that the separated flow attached on the wall in vicinity area to the position of $0.62 D$. In $1.12 D$ downstream of the elbow as in Fig. 12(a-3), axial flow profiles well corresponded to the experimental result.

Figure 13 (a), (b) and (c) show radial profiles of the time averaged axial velocity of FS at $R e=3.7 \times 10^{6}$ with water at $20{ }^{\circ} \mathrm{C}, \mathrm{FH}$ at $R e=8.0 \times 10^{6}$ with water at $60{ }^{\circ} \mathrm{C}$ and $\mathrm{FN}$ at $R e=1.4 \times 10^{7}$ with liquid-sodium at $550{ }^{\circ} \mathrm{C}$ in (a) $0.18 D$, (b) $0.62 \mathrm{D}$ and (c) $1.12 \mathrm{D}$ downstream from the elbow outlet. Lateral axes in Figs. 13(a) and (b) show the normalized time averaged axial velocity component $V / V_{0}$ and vertical axis in each figure shows normalized radial position from inner wall $(r / D=-0.5)$ to outer wall $(r / D=0.5)$ of the elbow. Difference of the numerical results among FS, FH and FN was small and they showed the same tendency in axial velocity profile at each position in Figs. 13(a) and (b), respectively. In $0.18 D$ downstream of the elbow as shown in Fig. 13(a), the numerical results of FS, FH and FN could predict the adverse flow in $r / D<0.2$ due to the flow separation in the elbow. In $0.62 D$ downstream of the elbow as shown in Fig. 13(b), the adverse flow already vanished and the local acceleration near the inner wall side $(r / D \sim-0.4)$ could be reproduced.

\subsubsection{Flow structure and pressure fluctuation generation}

Unsteady large scale eddy structure appearing a horseshoe shape was identified around the separation region and they could be visualized by iso-surface contour of the second invariant of velocity gradient tensor $Q \mathrm{~s}^{-2}$ defined by the following equations ${ }^{(8,10)}$.

$$
\begin{aligned}
& Q=\left(W_{i j} W_{i j}-D_{i j} D_{i j}\right) / 2 \\
& W_{i j}=\frac{1}{2}\left(\frac{\partial u_{i}}{\partial x_{j}}-\frac{\partial u_{j}}{\partial x_{i}}\right), \quad D_{i j}=\frac{1}{2}\left(\frac{\partial u_{i}}{\partial x_{j}}+\frac{\partial u_{j}}{\partial x_{i}}\right),
\end{aligned}
$$

Here, $D_{i j}$ is shear strain tensor and $W_{i j}$ is rotation component.

Figures 14(a), (b) and (c) show instantaneous pictures of flow structure described by iso-surface contour of second invariant of velocity gradient tensor $Q \mathrm{~s}^{-2}$ at a typical time step in FS, FH and FN. $Q=8,000 \mathrm{~s}^{-2}$ is at $V_{0}=9.2 \mathrm{~m} / \mathrm{s}$ as shown in Fig. 14. The similar large scale horseshoe eddy structure appeared in FS, FH and FN. The horseshoe shaped eddy structure also appeared in the unsteady Reynolds averaged Navier Stokes equation (URANS) simulation with the Reynolds stress model at the same conditions listed in Table $3^{(8)}$. The axial velocity fluctuation intensity at around $r / D=-0.25$ in Figs. $12(\mathrm{~b}-1),(\mathrm{b}-2)$ and (b-3) was caused by passing of the horseshoe eddies. The pressure inside the horseshoe eddy was low and the pressure between the horseshoe eddies was high as shown in Fig. 15(a). As movement of the horseshoe eddies by the stream, a significant cyclic pressure fluctuation could be induced in the pipe and on the wall surface. These flow patterns were 


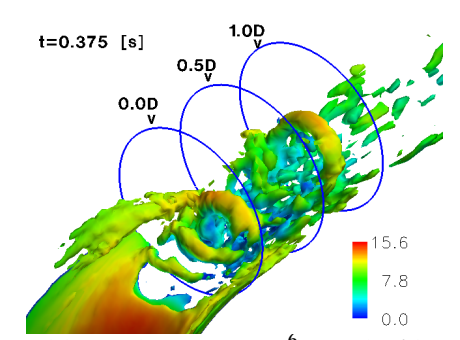

(a) $\operatorname{FS}\left(\operatorname{Re}=3.7 \times 10^{6}\right)$ $(\mathrm{m} / \mathrm{s})$

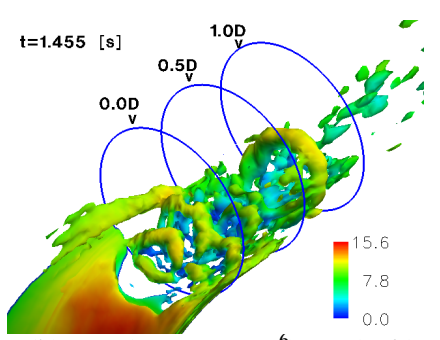

(b) $\mathrm{FH}\left(\operatorname{Re}=8.0 \times 10^{6}\right)$ $(\mathrm{m} / \mathrm{s})$

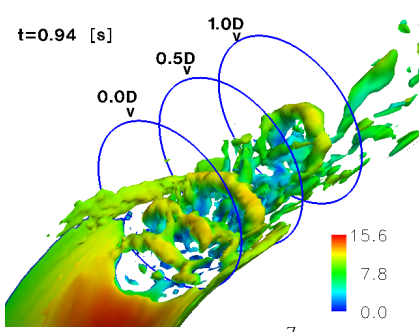

(c) $\mathrm{FN}\left(\operatorname{Re}=1.47 \times 10^{\prime}\right)$

$(\mathrm{m} / \mathrm{s})$

Fig. 14 Instantaneous vortex structure around pipe elbow outlet at several Reynolds number conditions. (Color-bar shows magnitude of the composed velocity $(\mathrm{m} / \mathrm{s})$.)

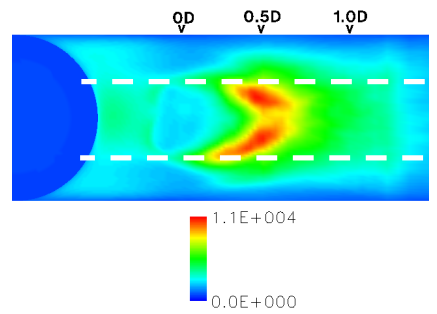

(a) $\quad(\mathrm{Pa})$

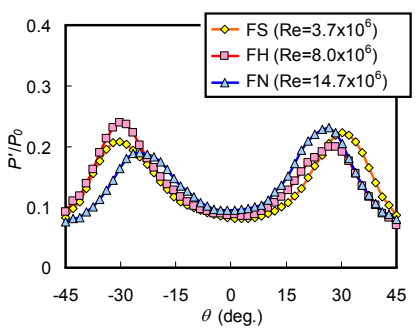

(b)

Fig. 15 (a) Pressure fluctuation intensity on the pipe surface on inner wall side in view from the inlet boundary at FS and (b) circumferential profile of pressure fluctuation intensity in $0.5 \mathrm{D}$ downstream from the elbow outlet of FS, FH and FN. (dotted lines in (a) are at \pm 30 degrees away from the bottom surface.)

consistent with those in the URANS simulation ${ }^{(8)}$.

Figures 15 (a) and (b) respectively show the pressure fluctuation intensity on the pipe surface by the view from the pipe inlet and the circumferential profile of pressure fluctuation intensity in $0.5 \mathrm{D}$ downstream from the elbow outlet. Dotted lines show the locations at +30 degrees from the bottom surface on the inner wall side. The pressure fluctuation intensity was high at around $0.5 D$ downstream from the elbow outlet according to unsteadiness of the re-attachment point from moment to moment. At the +30 degrees as boundary of the recirculation flow region, pressure fluctuation intensity was high as shown in Fig. 15 (a) and (b) because of the horseshoe structure passage. Dominant frequency of the pressure fluctuation at +30 degrees in $0.5 D$ downstream from the elbow outlet was at $S t=0.44 \sim 0.63$ in numerical results and this was close to that of $S t=0.45$ in the experiment ${ }^{(2)}$ and also that of $S t=0.54$ in the URANS simulation ${ }^{(8)}$. Kawamura et al., ${ }^{(20)}$ clarified that the axial velocity fluctuation had a dominant frequency component of $S t=0.5$ in the short-elbow at $r / D=-0.3$ and 45 degrees away from the bottom of the wall on inner side in $1 D$ downstream from the elbow outlet. In the numerical simulation, the dominant frequency of the axial velocity fluctuation appeared at $S t=0.46 \sim 0.57$ at the same position in the pipe.

The large-scale horseshoe-like eddy and also the unsteady secondary flow motion as shown in Fig. 9(b-2) existed around the separation region formed in the downstream of the short-elbow. It could be conjectured that pressure fluctuation with dominant frequency at approximately 0.5 in strouhal number could be generated by the interaction between the large-scale eddy motion and the unsteady secondary flow motion in the short-elbow pipe.

\section{Concluding Remarks}

Numerical simulations for several pipe elbows in different pipe diameters and curvature radii at a laminar flow condition and several turbulent flow conditions up to $R e=1.47 \times 10^{7}$ were conducted to investigate unsteady flow behavior through the short-elbow, including validation study of the in-house code MUGTHES. Though the simulations from a laminar flow condition to the high Reynolds number conditions, numerical schemes in MUGTHES were verified and applicability for the flow through the short- and long-elbows was 
confirmed. Fundamental characteristics of the flow structure in the short and long-elbows were clarified through the numerical simulations in relation between the pressure drop and the axial velocity transitions. And unsteady flow structure generation mechanism in shortelbow at turbulent flow condition was also discovered in comparison between the numerical results and the experimental results including empirical knowledge in literature. The secondary flow development and the flow separation formation in the elbow were much influenced by the velocity profile in upstream of the elbow and also the curvature radius. The flow separation could successively occur in the short-elbow pipe. In this numerical study, dependency of the flow pattern in the post-critical regime on the Reynolds number condition was small in the short-elbow pipe. Based on the numerical results, unsteady flow and pressure fluctuation generation in the short-elbow were characterized by the interaction of unsteady secondary flow and the large-scale horseshoe-like eddy motion in the elbow.

\section{References}

(1) Ichimiya, M., Mizuno, T. and Kotake, S., A Next Generation Sodium-Cooled Fast Reactor Concept and Its R\&D Program, Nuclear Engineering and Technology, Vol.39 (2007), pp.171-186.

(2) Shiraishi, T., Watakabe, H., Sago, H., Konomura M. and Yamaguchi, A., Fujii, T., Resistance and Fluctuating Pressures of a Large Elbow in High Reynolds Numbers, Journal of Fluids Engineering, Vol.128 (2006), pp.1063-1073.

(3) Iwamoto, Y., Kondo, M., Yasuda, K., Sogo, M., Tanaka, M. and Yamano, H., Study on Flow Induced Vibration Evaluation for A Large Scale JSFR Piping: (4) Unsteady Flow Characteristics in 1/10 Scale Hot-Leg Piping Experiments Under Undeveloped And Swirl Inflow Conditions, Proceedings of the 19th International Conference on Nuclear Engineering, (2011), ICONE19-43569.

(4) Ono, A. Kimura, N., Kamide, H. and Tobita, A., Influence of elbow curvature on flow structure at elbow outlet under high Reynolds number condition, Nuclear Engineering and Design, Vol.241 (2011), pp.4409-4419.

(5) Ebara, S., Aoya, Y., Sato, T., Hashizume, H., Yuki, K., Aizawa, K. and Yamano, H., Pressure Fluctuation Characteristics of Complex Turbulent Flow in Single Elbow with Small Curvature Radius for a Sodium-Cooled Fast Reactor, Journal of Fluids Engineering, Vol.132 (2010), pp.111102-1-7.

(6) Aizawa, K., Yamano, H., Kotake, S. and Fujimata, K., Numerical Calculation of Fluid Flow within a Large-Diameter Piping with a Short-Elbow in JSFR, Proceedings of the 7th International Topical Meeting on Nuclear Thermal-hydraulics, operations, and safety, (2008), Paper 039.

(7) Aizawa, K., Nakanishi, S., Yamano, H., Kotake, S., Hayakawa, S., Watanabe, O. and Fujimata, K., Study on Flow-Induced-Vibration Evaluation of Large-Diameter Pipings in a Sodium-Cooled Fast Reactor (1) Sensitivity Analysis of Turbulent Flow Models for Unsteady Short-Elbow Pipe Flow, Proceedings of 6th Japan-Korea Symposium on Nuclear Thermal Hydraulics and Safety, (2008), N6P1053.

(8) Tanaka, M., Ohshima, H., Yamano, H., Aizawa, K. and Fujisaki, T., U-RANS Simulation of Unsteady Eddy Motion in Pipe Elbow at High Reynolds Number Conditions, Proceedings of the 2010 International Congress on Advances in Nuclear Power Plants, (2010), Paper 10272.

(9) Eguchi, Y., Murakami, T., Tanaka, M., and Yamano, H., A Finite Element LES for High-Re Flow in A Short-Elbow Pipe with Undisturbed Inlet Velocity, Nuclear Engineering and Design, Vol.241 (2011), pp.4368-4378.

(10) Tanaka, M., Ohshima, H. and Monji, H., Numerical Investigation of Flow Structure in Pipe Elbow with Large Eddy Simulation Approach, Proceedings of the ASME 2009 Pressure Vessel and Piping Division Conference, (2009), PVP2009-77598. 
(11) Berger, S. A. and Talbot, L., Flow in Curved Pipes, Annual Review of Fluid Mechanics, Vol.15 (1983), pp.461-512.

(12) Dean, W. R., XVI. Note on the motion of fluid in a curved pipe, Philosophical Magazine Series 7, 4:20 (1927), pp.208-223.

(13) Dean, W. R., LXXII. The stream-line motion of fluid in a curved pipe (Second paper), Philosophical Magazine Series 7, 5:30 (1928), pp.673-695.

(14) Ito, H., Friction Factors for Turbulent Flow in Curved Pipes, Transaction of the ASME, Journal of Basic Engineering, (1959), pp.123-134.

(15) Ito, H., Pressure Losses in Smooth Pipe Bends, Transaction of the ASME, Journal of Basic Engineering, (1960), pp.131-143.

(16) Frried, E., Idelchik, I. E., Flow Resistance: A Design Guide for Engineers, Hemisphere Publishing Corporation, (1989), Chap. 2 and 6.

(17) Bovendeerd, P. H. M., van Steenhoven, A. A., van de Vosse, F. N. and Vossers, G., Steady Entry Flow in A Curved Pipe, Journal of Fluid Mechanics, Vol.177 (1987), pp.233-246.

(18) Enayat, M. M., Gibson, M. M., Taylor, A. M. K. P. and Yianneskis, M., Laser-Doppler Measurements of Laminar and Turbulent Flow in A Pipe Bend, International Journal of Heat and Fluid Flow, Vol.3, No.4 (1982), pp.213-219.

(19) Sudo, K., Takami, T. and Yano, K., Turbulent Flow in a Circular-Sectioned $90^{\circ}$ Bend, Transactions of the Japan Society of Mechanical Engineers, Series B, Vol.58, No.548 (1992), pp.1015-1021. (in Japanese)

(20) Kawamura, T., Nakao, T. and Takahashi, M., Reynolds Number Effect on Turbulence downstream from Elbow Transactions of the Japan Society of Mechanical Engineers, Series B, Vol.68, No.667 (2002), pp.645-651. (in Japanese)

(21) Yuki, K., Kumano, T., Toda, S., Hashizume, H. and Muramatsu, T., Unsteady Decay Behavior of Secondary Flow Generated in a90-Degree Bends, Transactions of the Japan Society of Mechanical Engineers, Series B, Vol.70, No.693 (2004), pp.11631170. (in Japanese)

(22) Coffield, R. D., Hammond, R. B., Koczko, J. P., McKeown, P. T. and Zirpoli, P. J., Irrecoverable Pressure Loss Coefficients for A Short Radius of Curvature Piping Elbow at High Reynolds Numbers, WAPD-T-3190, (1998).

(23) Tanaka, M., Ohshima, H. and Monji, H., Numerical Simulation of Thermal Striping Phenomena in a T-Junction Piping System Using Large Eddy Simulation, Journal of Power and Energy Systems, Vol.3, No.1 (2009), pp.237-248.

(24) Tanaka, M., Ohshima, H. and Monji, H., Thermal Mixing in T-Junction Piping System related to High-Cycle Thermal Fatigue in Structure, Journal of Nuclear Science and Technology, Vol.47, No.9 (2010), pp.790-801.

(25) Tannenhill, J. C., Anderson, D. A. and Pletcher, R. H., Computational Fluid Mechanics and Heat Transfer 2nd Edition, Taylor \& Francis, (1997), Sec.5.7.

(26) Pope, S. B., Turbulent Flows, Cambridge University Press, (2000), Chap.13.

(27) Chorin A. J., Numerical Solution of the Navier-Stokes Equations, Mathematics of Computation, Vol.22 (1968), pp.745-762.

(28) Batchelor, G. K., An Introduction to Fluid Dynamics, Cambridge University Press, (1967), Sec. 5.10.

(29) Schlichting, H., Gersten, K., Boundary Layer Theory 8th Revised and Enlarged Edition, Springer, (2000), Sec.1.6.

(30) Dean, R. C. Jr., Separation and Stall Handbook of Fluid Dynamics, McGraw-Hill, (1970), Chap.11.

(31) Pigott, R. J. S., Losses in Pipe and Fittings, Tranaction of the ASME, Vol.79, No.8 (1957), pp.1767-1783.

(32) Iwamoto, Y., Yasuda, K., Sogo, M., Yamano, H. and Kotake, S., Study on Flow- 
Induced-Vibration Evaluation of Large-Diameter Pipings in a Sodium-Cooled Fast Reactor (4) Experiments on the 1/10-Scale Hot Leg Test Facility in Reynolds Number of 50000 and 320000, Proceedings of 6th Japan-Korea Symposium on Nuclear Thermal Hydraulics and Safety, (2008), N6P1010.

(33) Yuki, K. Yoshida, K., Hashizume, H. and Toda, S., Matched refractive-index PIV measurement of complex flow structure in a two-dimensional dual elbow, Proceedings of the 7th International Topical Meeting on Nuclear Thermal-hydraulics, operations, and safety, (2008), Paper 226. 